\title{
Durabilidade de peças cerâmicas vermelhas com adição de rejeito de rocha ornamental isenta de granalha
}

\section{(Durability of red ceramic samples with addition of ornamental rock waste free of steel particles)}

\author{
D. V. Rodrigues, G. C. Xavier ${ }^{l}$, F. Saboya, P.C.A Maia, J.Alexandre \\ Laboratório de Engenharia Civil - LECIV, Universidade Estadual do Norte Fluminense, Av. Alberto \\ Lamego 2000, Horto, Campos dos Goytacazes, RJ 28013-600 \\ gxavier@uenf.br
}

\begin{abstract}
Resumo
Para avaliação da degradação acelerada em laboratório sofrida pelos corpos de prova de cerâmica vermelha com adição de rejeito de rocha ornamental isento de granalha, foi utilizado um equipamento que lixivia com água quente e fria em tempos controlados, e também, congela a amostra em até $-4{ }^{\circ} \mathrm{C}$. Os corpos de prova cerâmicos foram confeccionados com até $10 \%$ em massa de rejeito de rocha ornamental a seco, e em seguida, umedecidos e moldados por extrusão. Os materiais produzidos foram calcinados nas temperaturas de $700{ }^{\circ} \mathrm{C}, 800{ }^{\circ} \mathrm{C}$ e $900{ }^{\circ} \mathrm{C}$. Após $1060 \mathrm{~h}$ de degradação acelerada em equipamento de laboratório, analisaram-se as propriedades cerâmicas do material. Os resultados das resistências mecânicas foram comparados através da distribuição de Weibull, antes e depois da degradação. Nota-se que o material com adição de $10 \%$ de rejeito de rocha ornamental na massa cerâmica é mais confiável quando queimada a $900^{\circ} \mathrm{C}$ após a degradação, quando comparados com as amostras sem adição de rejeito, proporcionando maior durabilidade.
\end{abstract}

Palavras-chave: cerâmica vermelha, resíduo de rocha ornamental, durabilidade, distribuição de Weibull.

Abstract

For the evaluation of the accelerated degradation in laboratory of red ceramic specimens with addition of ornamental rock waste free from steel particles, an equipment that leach with hot and cool water and time control, and also freezing the specimen at $-4{ }^{\circ} \mathrm{C}$ was used,. The ceramic samples were made with up to $10 \mathrm{wt} \%$ of the dry ornamental rock waste, and after humidifying and molding by extrusion. The specimens were fired at $700{ }^{\circ} \mathrm{C}, 800{ }^{\circ} \mathrm{C}$ and $900{ }^{\circ} \mathrm{C}$. After $1060 \mathrm{~h}$ of accelerated degradation lab test, ceramic properties were evaluated. The results of the strength were compared for Weibull distribution, before and after degradation. The specimens with addition of $10 \mathrm{wt} \%$ waste is more durable and reliable when fired to $900{ }^{\circ} \mathrm{C}$ after the degradation.

Keywords: red ceramic, ornamental rock waste, durability, Weibull distribution.

\section{INTRODUÇÃO}

O estado do Espírito Santo, em virtude de sua posição geográfica privilegiada, destaca-se como um grande pólo industrial de granito e mármore, contribuindo com $43 \%$ da produção nacional, levando o país à quinta maior produção mundial de rochas em volume [1]. Os rejeitos gerados durante o desdobramento de rochas, quando lançados nos ecossistemas sem quaisquer cuidados, representam um risco em potencial à saúde pública e ao meio ambiente [2]. No Espírito Santo são gerados $\sim 152000 \mathrm{~m}^{3}$ de rejeitos do processo de beneficiamento de rochas ornamentais no ano [3]. A obtenção de materiais de construção por meio de pesquisas com esses rejeitos, principalmente em cerâmica vermelha, faz com que as indústrias desenvolvam tecnologias alternativas, favorecendo um menor comprometimento ao meio ambiente. Foi mostrada a viabilidade técnica de se incorporar rejeitos do segmento de rochas ornamentais em cerâmica vermelha na fabricação de tijolos e telhas, vislumbrando a melhoria da qualidade mecânica e da trabalhabilidade de massa industrial [4-7]. Para produtos com valor agregado maior como revestimento cerâmico foi observado que a incorporação em até $40 \%$ de resíduo de rocha ornamental apresenta diferenças significativas no comportamento de queima de uma típica massa industrial de revestimento cerâmico semiporoso, agregando valor ao resíduo [8].

As peças cerâmicas vermelhas quando expostas ao tempo apresentam facilmente um processo de degradação. Com a finalidade de minimizar os impactos causados e garantir ao material uma maior durabilidade, neste trabalho introduziu-se o rejeito de rocha ornamental na massa de argila. Esse rejeito é proveniente de blocos de rocha desdobrados em teares de fio diamantado, significando que não possui granalha. Aos poucos estes teares estão substituindo os convencionais devido à maior eficiência e menor manutenção, além de não introduzir no rejeito a fração metálica. Quando as peças cerâmicas entram em contato com as condições atmosféricas, ocorre uma modificação em 
suas propriedades físicas e químicas, podendo comprometer seu comportamento mecânico [9].

Com o intuito de simular as condições intempéricas naturais de forma acelerada em laboratório, as amostras foram submetidas a ciclos de lixiviação de água quente/ vapor d'água $\left(70^{\circ} \mathrm{C}\right)$ e água fria $\left(21^{\circ} \mathrm{C}\right) \mathrm{em}$ um equipamento de degradação de laboratório. Os ciclos são de água quente e fria com temperaturas e tempos controlados por meio de uma caixa de comando. Além disso, este equipamento submete a amostra ao congelamento em até $-4{ }^{\circ} \mathrm{C}$. Os mecanismos simulados de forma acelerada são: variação de temperatura do ar provocada pela radiação solar durante o dia e temperaturas mais baixas durante a noite, chuvas e umidade relativa do ar umedecendo e expandindo as peças cerâmicas.

Para descrever o comportamento de fratura do material cerâmico, quando submetido a um dado nível de tensão, foi utilizada a distribuição de Weibull [10]. Tendo em vista que, quanto maior o número de defeitos estruturais nas peças, maior será a probabilidade de falhas. Portanto, o que determina a resistência mecânica de um material é a existência de falhas críticas na região de máxima solicitação [11]. A equação A descreve a distribuição de Weibull:

$$
f(\sigma)=\frac{m}{\sigma_{R}}\left(\frac{\sigma-\sigma_{0}}{\sigma_{R}}\right)^{m-1} \exp \left\{-\left(\frac{\sigma-\sigma_{0}}{\sigma_{R}}\right)^{m}\right\}
$$

na qual $\sigma_{0}$ é a tensão antes da qual o material não falhará, $\sigma_{\mathrm{R}}$ é um valor referencial de tensão, correspondente a 0,632 de probabilidade de falha do material e $\mathrm{m}$ é o módulo de Weibull, relacionado à dispersão das medidas.

Este trabalho tem o objetivo de caracterizar os materiais envolvidos e analisar a degradação das propriedades tecnológicas de cerâmica vermelha incorporada com rejeito de rocha ornamental. A distribuição de Weibull foi utilzada para se verificar, a partir de uma dada temperatura considerada por esta estatística, a maior confiabilidade dos materiais envolvidos.

\section{MATERIAIS E MÉTODOS}

A argila utilizada para a confecção das amostras é oriunda de Campos, RJ [12, 13]. O rejeito de rocha, proveniente do desdobramento de blocos de rochas ornamentais por tear de fio diamantado, é de Cachoeiro do Itapemirim, ES. Este material é livre de granalha.

Os ensaios realizados determinaram as distribuições do tamanho de partículas do rejeito e também da massa argilosa utilizada, via úmido por peneiramento e sedimentação, segundo a NBR-7181 (1984) [14]. As amostras foram passadas na peneira ABNT 325 (abertura 0,045 mm) e secas em estufa a $110{ }^{\circ} \mathrm{C}$. Foi utilizado o equipamento de energia dispersiva de raios X Shimadzu EDX-700. Para a perda ao fogo das amostras foi utilizado um forno na temperatura de queima de $950{ }^{\circ} \mathrm{C}$ e posteriormente, verificada a perda de massa após queima. A composição mineralógica foi obtida por difração de raios X, em equipamento Shimadzu DXR 7000, operando com radiação $\mathrm{Cu}-\mathrm{k} \alpha$ e $2 \theta$ variando de $5^{\circ}$ a $80^{\circ}$.

A degradação acelerada dos corpos de prova cerâmicos foi realizada em um equipamento de degradação de laboratório (Fig. 1). Este equipamento submete as amostras a tempos controlados de lixiviação contínua de água destilada quente $\left(70{ }^{\circ} \mathrm{C}\right)$ ou fria $\left(21^{\circ} \mathrm{C}\right)$, com controle de temperatura da câmara de amostras, e também submete as amostras ao congelamento em até $-4{ }^{\circ} \mathrm{C}$. Além disso, as amostras ficam sujeitas à atmosfera de vapor toda vez que o ciclo de água quente entra em funcionamento.

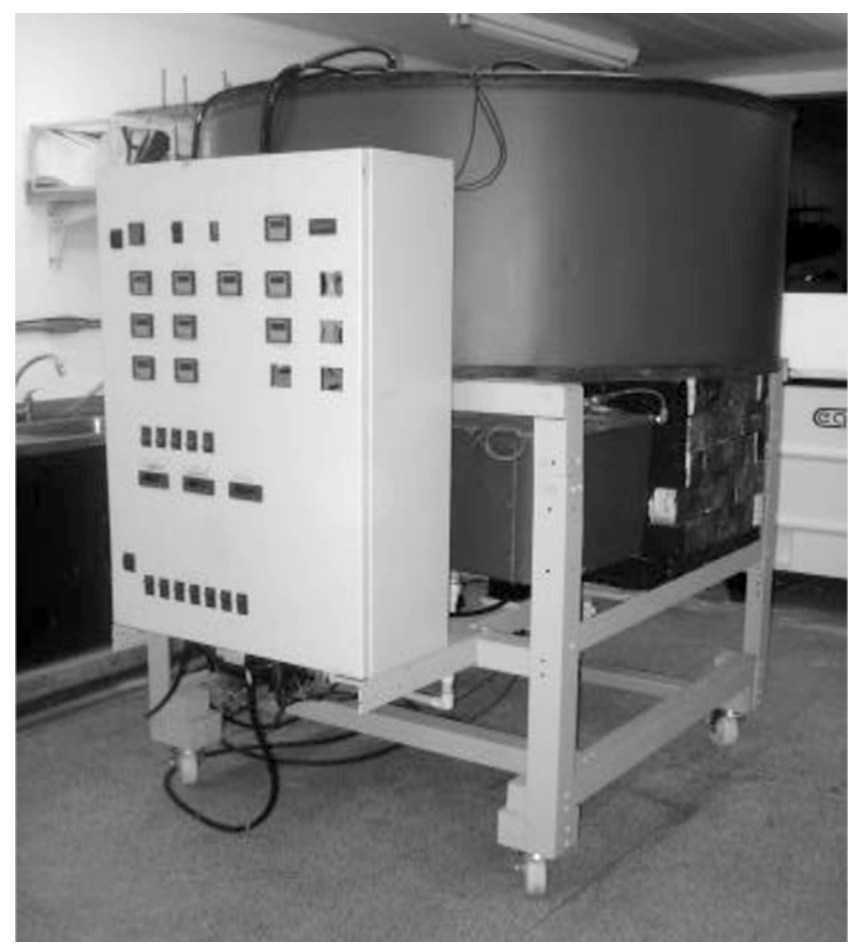

Figura 1: Equipamento de degradação de laboratório .

[Figure 1: Laboratory weathering device.]

A preparação da massa argilosa iniciou com a desagregação da argila com auxílio de destorroador mecânico, coletada na indústria cerâmica em forma de torrões com tamanhos variados. O material, então, foi passado na peneira ABNT 10 (abertura 2,0 mm). Foram preparadas misturas com diferentes porcentagens de rejeito, $0 \%(0 \mathrm{R})$, $5 \%(5 R)$ e $10 \%$ (10R) em massa. Estas composições foram levadas para estufa a $110{ }^{\circ} \mathrm{C}$ e homogeneizadas a seco e umedecidas com água a um percentual $35,45 \%$, calculado na equação (B) [15]:

$$
\text { Wext. }=\frac{L L}{2}+2 \%
$$

na qual LL é o limite de liquidez [16] do material dado em porcentagem.

Para simular as condições reais das cerâmicas, o material foi passado duas vezes em laminador, critério adotado por apresentar melhores resultados de densificação das massas para argilas de Campos, RJ [17]. Após a dupla laminação 
as massas cerâmicas foram levadas para extrusora de laboratório sob pressão de $0,07 \mathrm{MPa}(20 \mathrm{pol} / \mathrm{Hg})$ para o processo de conformação. As amostras obtidas nesta fase foram medidas e pesadas úmidas, secas a $110^{\circ} \mathrm{C}$, depois da queima a $700{ }^{\circ} \mathrm{C}, 800{ }^{\circ} \mathrm{C}, 900{ }^{\circ} \mathrm{C}$. A taxa de aquecimento foi $2{ }^{\circ} \mathrm{C} / \mathrm{min}$, patamar de queima $3 \mathrm{~h}$ e a atmosfera oxidante. Estas temperaturas foram escolhidas em função das temperaturas de utilização da indústria cerâmica de Campos, RJ e que a temperatura de $700{ }^{\circ} \mathrm{C}$ é a mais utilizada. O tempo das amostras no equipamento de degradação foi de 41,67 dias (1000 h). Este tempo de exposição das amostras no equipamento de degradação está sendo estudado para calibração do equipamento. Os corpos de prova prismáticos moldados por extrusão possuem dimensões médias de 10,50 $\mathrm{cm}$ de comprimento, $2,70 \mathrm{~cm}$ de largura e $1,70 \mathrm{~cm}$ de altura. Após a queima e processo de degradação, as peças cerâmicas foram levadas ao laboratório e definidas suas propriedades tecnológicas $[18,19]$. Os resultados apresentam a média de 20 amostras.

\section{RESULTADOS E DISCUSSÃO}

Distribuição do tamanho de partículas do rejeito de rocha e da massa argilosa

A Fig. 2 mostra as curvas da distribuição do tamanho de partículas via úmida por peneiramento e sedimentação segundo a norma [14].

Analisando a Fig. 2a, a massa argilosa apresenta 53,3\% de fração argila, $38,2 \%$ de fração silte e $8,5 \%$ de fração areia, caracterizando-a como uma argila plástica típica para uso cerâmico. Comparando com [12], verifica-se que a massa argilosa é muito plástica. Verifica-se na Fig. 2b que a distribuição do tamanho de partículas do rejeito de rocha é predominantemente de fração silte de $67 \%$, apresentando-se como um pó mineral fino e uniforme, podendo ser utilizado como redutor de plasticidade da massa cerâmica. Como este último material é fino, não haveria a necessidade de mudar a planta industrial para redução do tamanho de partículas, sendo então, indicado para uso cerâmico.

\section{Análise química quantitativa}

A Tabela I apresenta as composições químicas da massa argilosa e do rejeito de rocha.

A argila (Tabela I) apresentou perda ao fogo (P.F.) de $12,30 \%$, sendo considerada elevada, mostrando que a fração argila (Fig. 2 a - 53,3\%) é predomiante. A composição de $\mathrm{SiO}_{2}+\mathrm{Al}_{2} \mathrm{O}_{3}$ acima de $84 \%$ caracteriza a massa argilosa como um material plástico adequado ao uso em cerâmica vermelha. A coloração da argila após a queima é função dos $8,87 \%$ de $\mathrm{Fe}_{2} \mathrm{O}_{3}$. $\mathrm{O} \mathrm{K} \mathrm{K}_{2} \mathrm{O}$ e $\mathrm{CaO}$ presentes na argila na proporção de $3,17 \%$ e $0,54 \%$ respectivamente, são agentes fundentes na queima e forma fase líquida, contribuindo para a redução da porosidade do material. A perda ao fogo de $0,39 \%$ do rejeito de rocha mostra a estabilidade deste material ao tratamento térmico. $\mathrm{O}$ teor de sílica do rejeito de rocha é de aproximadamente $50 \%$ e o de $\mathrm{Al}_{2} \mathrm{O}_{3}$ é superior a)



b)

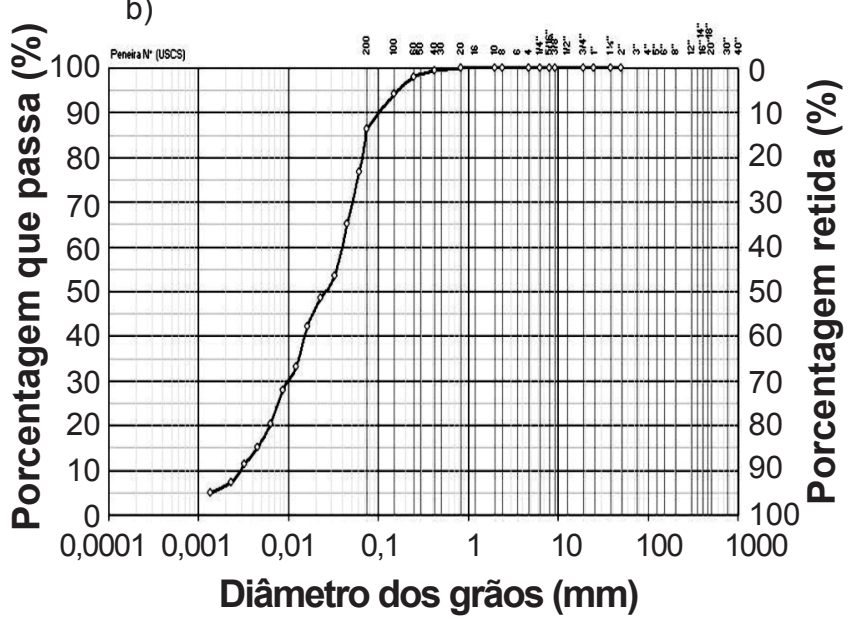

Figura 2: Curvas de distribuição do tamanho de partículas do rejeito e da massa argilosa.

[Figure 2: Particle size distribution curves of the clay and waste.]

Tabela I - Composições químicas quantitativas.

[Table I - Chemical composition of the clay and waste.]

\begin{tabular}{|c|c|c|c|c|c|c|c|}
\hline $\begin{array}{c}\text { Matérias } \\
\text { Primas }\end{array}$ & $\begin{array}{l}\text { P.F. } \\
(\%)\end{array}$ & $\begin{array}{c}\mathrm{SiO}_{2} \\
(\%)\end{array}$ & $\begin{array}{c}\mathrm{Al}_{2} \mathrm{O}_{3} \\
(\%)\end{array}$ & $\begin{array}{c}\mathrm{Fe}_{2} \mathrm{O}_{3} \\
(\%)\end{array}$ & $\begin{array}{l}\mathrm{K}_{2} \mathrm{O} \\
(\%)\end{array}$ & $\begin{array}{l}\mathrm{CaO} \\
(\%)\end{array}$ & $\begin{array}{c}\text { Outros } \\
\text { óxidos } \\
(\%)\end{array}$ \\
\hline Argila & 12,3 & 48,83 & 35,46 & 8,87 & 3,17 & 0,54 & 3,09 \\
\hline Rejeito & 0,39 & 50,09 & 17,6 & 12,47 & 3,7 & 12,39 & 3,75 \\
\hline
\end{tabular}


a $17 \%$, indicando se tratar de composições químicas de minerais primários (quartzo, feldspato e minerais do grupo da mica). O teor de $\mathrm{Fe}_{2} \mathrm{O}_{3}(12,48 \%)$ contribui para a coloração vermelha da peça após mistura com a argila. $\mathrm{O} \mathrm{K}_{2} \mathrm{O}(3,70 \%)$ e $\mathrm{CaO}(12,39 \%)$ presentes no rejeito são importantes na queima por reduzir os poros do material acabado.

\section{Análise mineralógica por difração de raios $X$}

A Fig. 3 apresenta os difratogramas de difração de raios $\mathrm{X}$ da argila e do rejeito.

Observa-se na Fig. $3 \mathrm{~b}$ a caulinita $\left(\mathrm{Al}_{2} \mathrm{O}_{3} \cdot 2 \mathrm{SiO}_{2} \cdot 2 \mathrm{H}_{2} \mathrm{O}\right)$, quartzo $\left(\mathrm{SiO}_{2}\right)$ e feldspato no difratograma de raios $\mathrm{X}$ da argila. A massa argilosa é predominantemente formada de caulinita. Na Fig. 3a o difratograma de raios $\mathrm{X}$ do rejeito de rocha mostra ortoclásio (feldspato sódico - $\mathrm{NaAlSi}_{3} \mathrm{O}_{8}$ ). Nota-se também quartzo $\left(\mathrm{SiO}_{2}\right)$ e minerais do grupo da mica. Os minerais primários feldspato e mica possuem na sua composição os alcalinos e alcalinos terrosos $\left(\mathrm{K}_{2} \mathrm{O}\right.$ e $\left.\mathrm{Na}_{2} \mathrm{O}\right)$, que contribuem na formação de fase líquida na sinterização, podendo preencher os poros das peças cerâmicas.

\section{Análise morfológica}

Na Fig. 4 são apresentadas imagens mostrando a morfologia e dimensões das partículas da massa cerâmica e do resíduo obtidas por microscopia eletrônica de varredura. A amostra de argila (Fig. 4a) apresentou textura grosseira e uma microestrutura porosa. Foi evidenciada a formação em placas de perfil irregular e lamelar, com contornos aparentemente hexagonais característico da caulinita. $\mathrm{Na}$ Fig. 4 b notam-se no resíduo de rocha, a morfologia irregular com cantos angulosos e estruturas alongadas das partículas, os aglomerados formando partículas maiores. Uma partícula de quartzo foi observada. As partículas de argila e de resíduo de rocha apresentam formas (obtidas nas imagens do MEV)
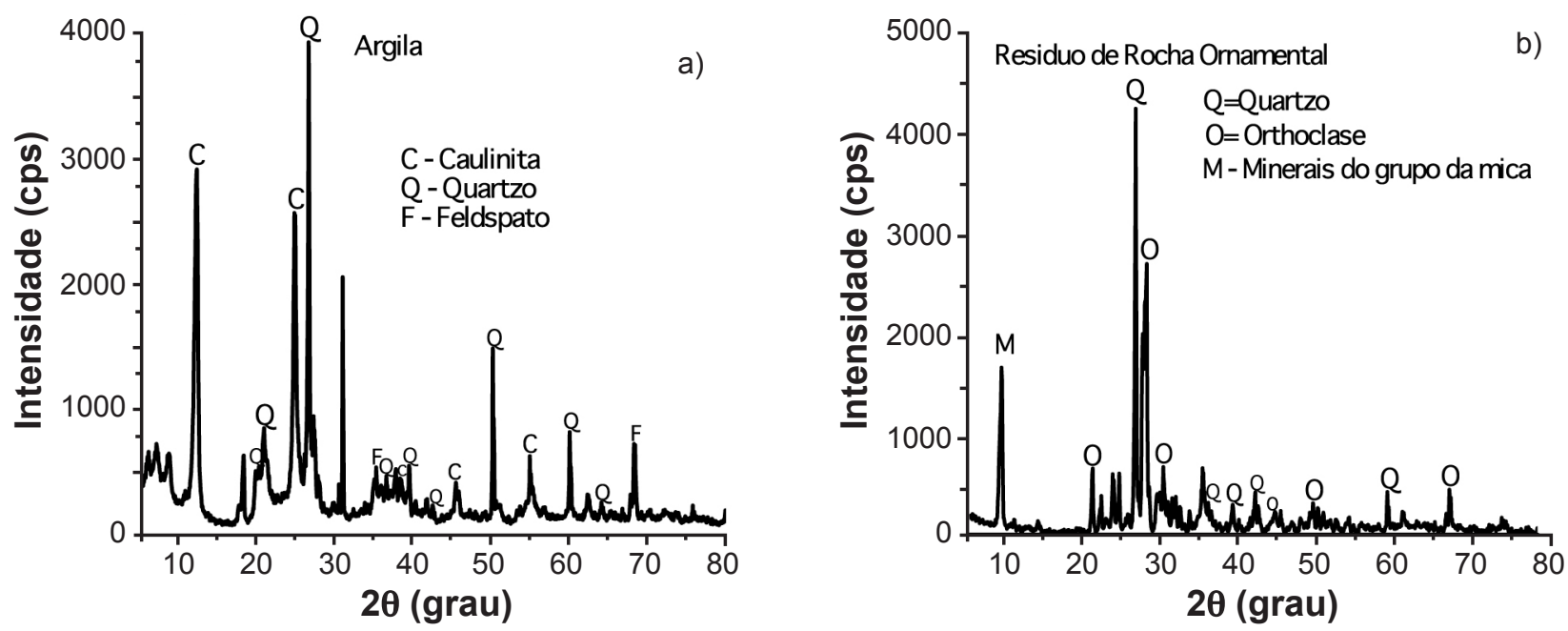

Figura 3: Difratogramas de raios $X$ da argila (a) e do rejeito de rocha (b). [Figure 3: X-ray diffraction patterns of the clay (a) and waste (b).]
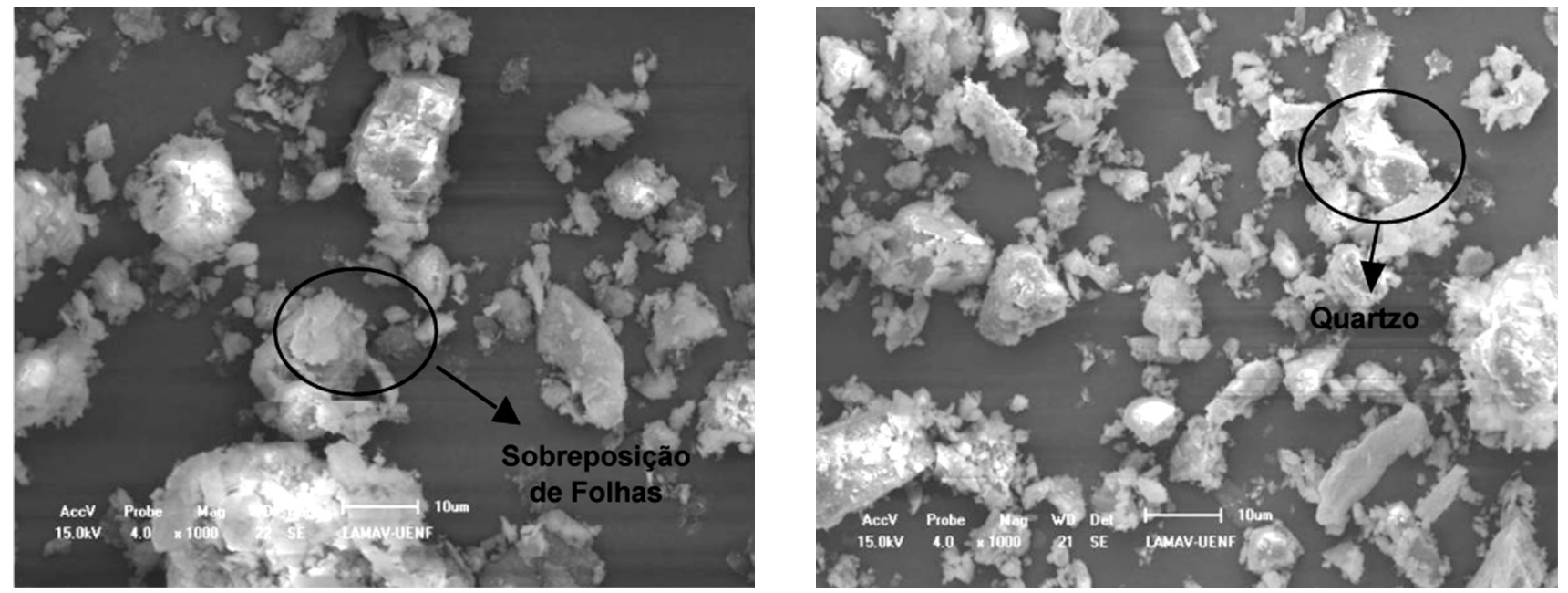

Figura 4: Imagens de microscopia eletrônica de varredura da argila (a) e do resíduo (b) com 1.000 vezes de aumento. [Figure 4: Scanning electron microscopy images of the clay (a) and waste (b).] 
que, quando misturadas a seco e depois conformadas, sugere que ocorrerá maior empacotamento entre partículas.

\section{Propriedades físico-mecânicas}

Após a queima, foram realizados os ensaios físicomecânicos para as misturas de $0 \%$ até $10 \%$ de rejeito de rocha em massa e os resultados estão mostrados a seguir nas Figs. 5 e 6 para corpos de prova não submetidos à degradação e na Fig. 7 antes e depois da degradação.

Os resultados da absorção de água da Fig. 5a apresentam valores entre 25 a $27 \%$ sem adição de rejeito; porém, somente a $900{ }^{\circ} \mathrm{C}$ o valor da absorção é menor significativamente devido a não transposição do desvio padrão. Com a adição de $5 R$ as amostras não apresentam diferenças significativas entre as temperaturas estudadas, observando-se apenas uma redução para $24,5 \%$ a 900 ${ }^{\circ} \mathrm{C}$. Com adição de $10 \mathrm{R}$ houve uma redução da absorção significativa a $900{ }^{\circ} \mathrm{C}$, com o limite inferior do desvio em $23 \%$ podendo ser devido aos óxidos fundentes, conforme a Tabela I. Quando se avalia os valores médios observa-se a tendência de redução da absorção de água com a adição de rejeito de rocha, conforme obtidos $[4,20]$ neste percentual de adição. Os resultados para a porosidade aberta da Fig.
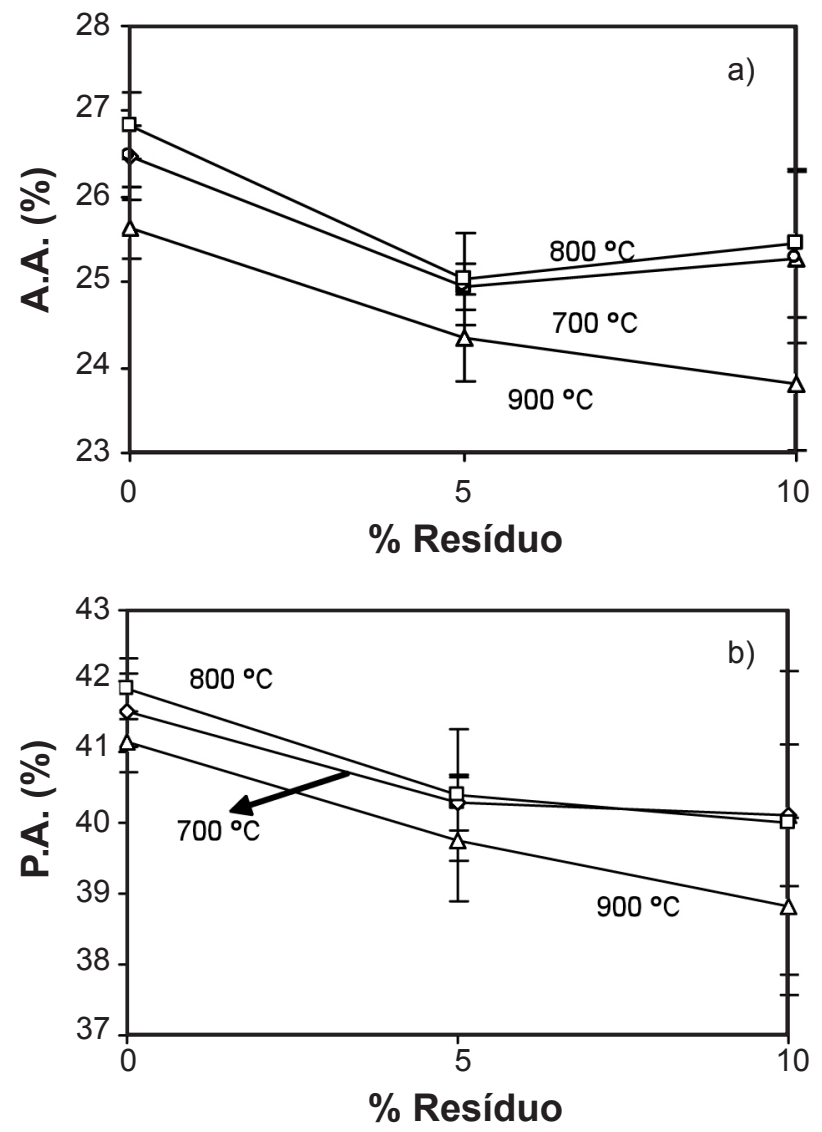

Figura 5: (a) Absorção de água e (b) porosidade aparente das peças cerâmicas adicionadas com rejeito de rocha ornamental, respectivamente.

[Figure 5: (a) Water absorption and (b) apparent porosity of red ceramic samples addition with ornamental rock waste.] 5b são semelhantes, inclusive na tendência das curvas de reduzirem estas propriedades com a adição de rejeito, independente da temperatura de queima.
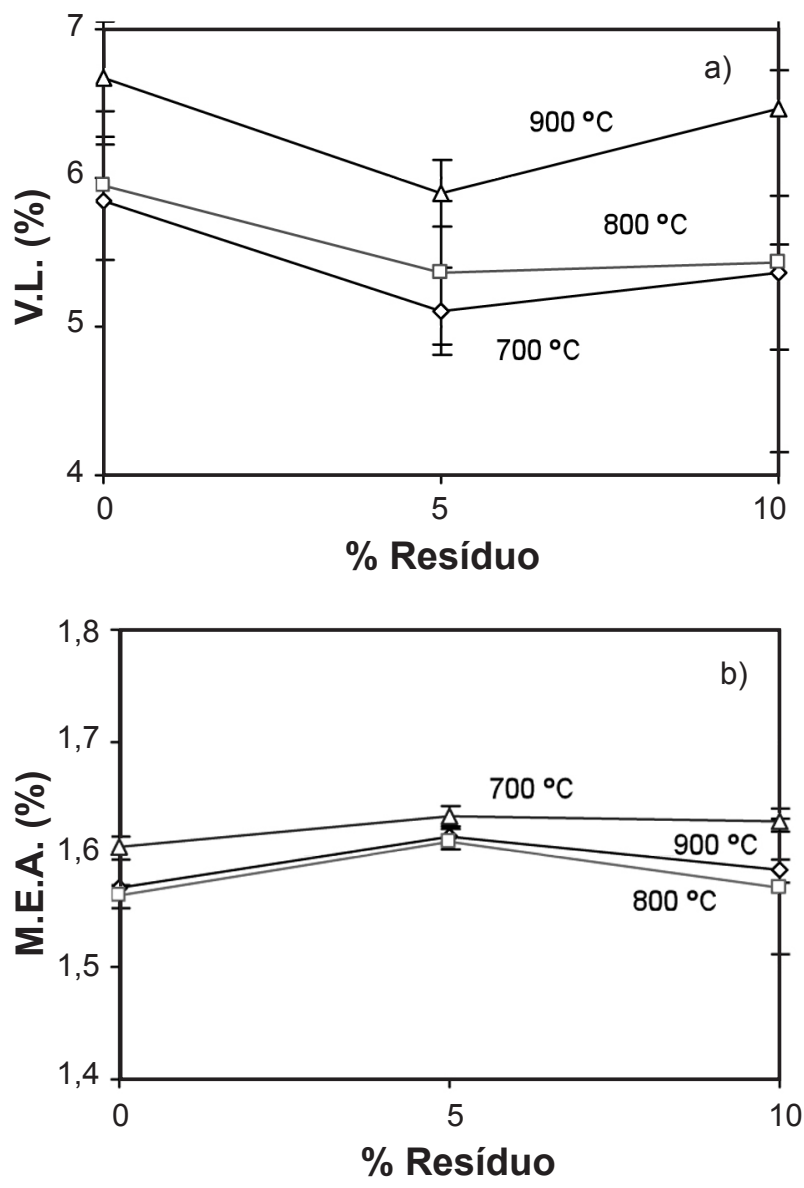

Figura 6: (a) Variação lineare (b) massa específica aparente das peças cerâmicas incorporadas com rejeito de rocha, respectivamente.

[Figure 6: (a) Linear Shrinkage and (b) Bulk density of red ceramic samples addition with ornamental rock waste.]

Para a retração linear indicada da Fig. 6 a não foi visto diferença significativa para esta propriedade nas temperaturas de queima. Pode-se afirmar que existe uma tendência de redução na retração linear quando se adiciona rejeito de rocha ornamental. No caso da massa específica (Fig. 6b), tende a aumentar com a adição de rejeito. Estes resultados de variação linear e massa específica podem contribuir para reduzir os defeitos internos e superficiais das peças cerâmicas $[7,8]$.

Comparando a Fig. 7a com a 7b não é observada degradação representativa nas amostras $0 \mathrm{R}$ a $700{ }^{\circ} \mathrm{C}$. A perda de resistência é observada nas amostras $0 \mathrm{R}$ queimadas a $800{ }^{\circ} \mathrm{C}$, de $4,8 \mathrm{MPa}$ para $4 \mathrm{MPa}$. A $900{ }^{\circ} \mathrm{C}$ há a tendência de incremento da resistência à flexão, observando-se somente um aumento significativo nas amostras com 10R. As amostras a $900{ }^{\circ} \mathrm{C}$ em todas as adições tendem ao enrijecimento. De modo geral as peças cerâmicas $0 \mathrm{R}$, $5 R$ e 10R não apresentaram diferenças significativas antes e depois do processo de degradação acelerada. Com isso 

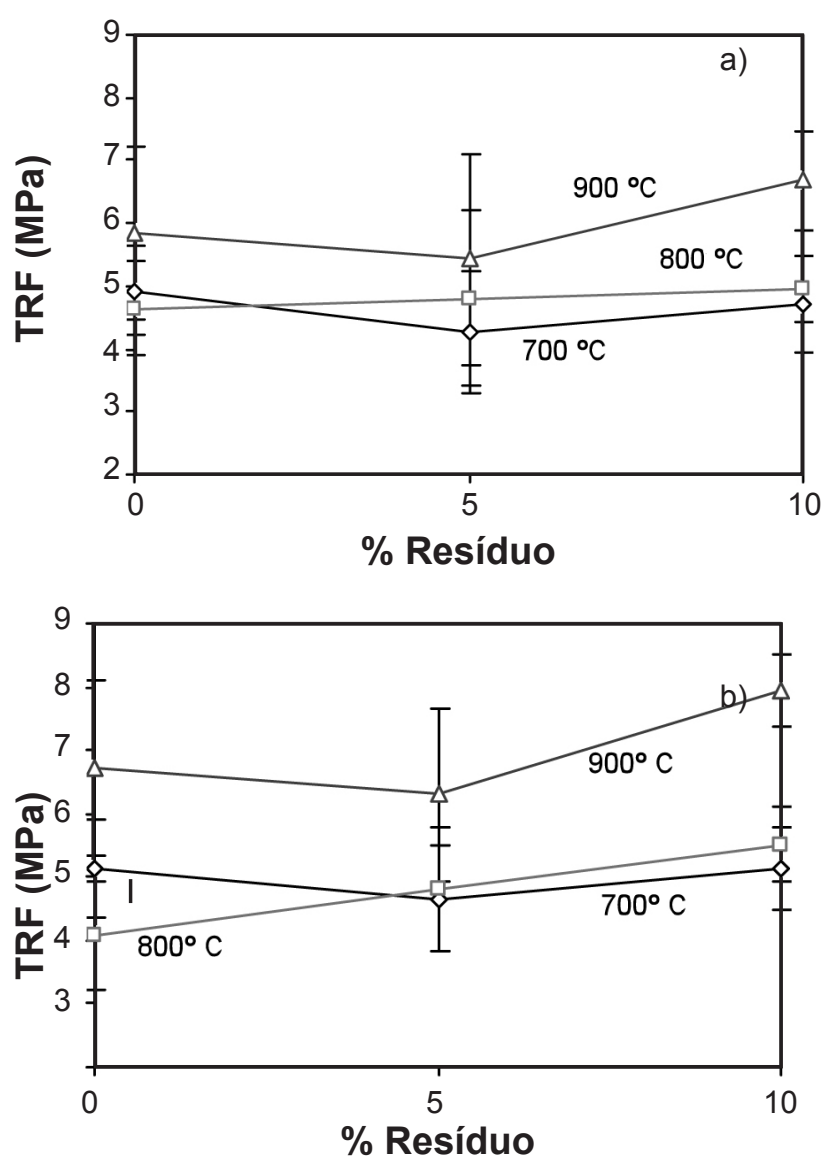

Figura 7: Tensão de ruptura à flexão das peças cerâmicas incorporadas com rejeito de rocha, antes (a) e depois (b) da degradação.

[Figure 7: (a) and (b) Flexural strength before (a) and after (b) degradation process of the ceramic pieces.]

torna-se necessário utilizar a estatística de Weibull para avaliar aos lotes de amostras com maior tendência de falhar quando submetido às cargas de trabalho.

A Fig. 8 apresenta o diagrama da distribuição de Weibull para as amostras 0R para se obter a temperatura com menor probabilidade de falha.

Para o diagrama de distribuição de Weibull foram analisados somente as amostras queimadas a $800{ }^{\circ} \mathrm{C}$ e 900 ${ }^{\circ} \mathrm{C}$. A temperatura de $700{ }^{\circ} \mathrm{C}$ foi desprezada uma vez que as peças cerâmicas não sofreram mudanças significativas após a degradação. A partir deste diagrama determina-se o módulo m de Weibull, que também é considerado como o valor a partir do qual há o risco de ruptura, bem como caracteriza a dispersão dos dados da tensão de ruptura dos corpos de prova [4]. Quanto maior o módulo de Weibull, mais homogênio e confíavel é o material.

Na Fig. 8 os valores dos módulos $\mathbf{m}$ de Weibull estão bem próximos, comparando os resultados antes e depois da degradação. Há uma pequena diminuição do seu valor quando queimados a $900{ }^{\circ} \mathrm{C}$. Observa-se também o deslocamento da reta para a direita a $900{ }^{\circ} \mathrm{C}$, onde a tensão de ruptura é maior. Maior confiabilidade está na amostra a

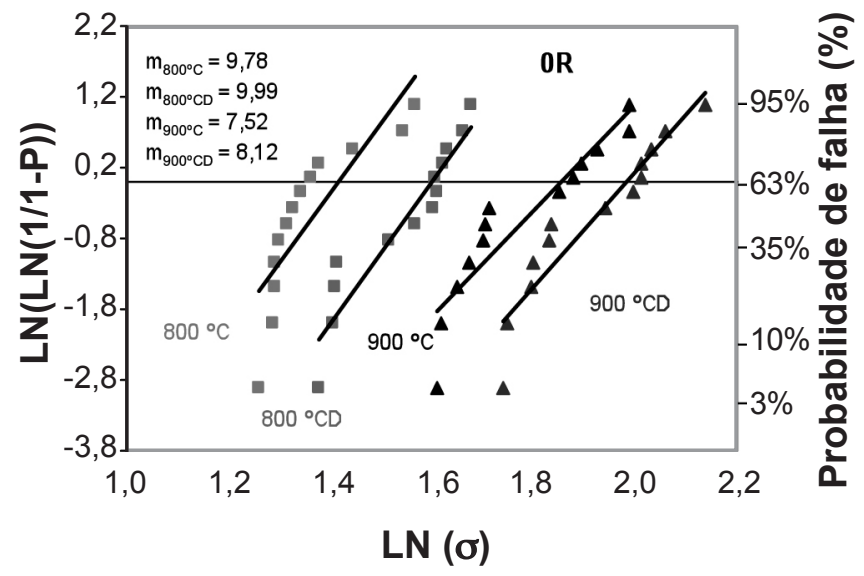

Figura 8: Distribuição de Weibull das peças cerâmicas 0R. [Figure 8: Weibull distribution of the standard specimen.]

$800{ }^{\circ} \mathrm{C}$ após o processo de degradação, na qual $\mathbf{m}$ foi 9,99 .

Com adição de 5R de rejeito na peça cerâmica (Fig. 9) o comportamento dos materiais foi bem próximo com os de $0 R$. Aqueles queimados a $800{ }^{\circ} \mathrm{C}$ com módulo $\mathbf{m}$ maior do que a $900{ }^{\circ} \mathrm{C}$, porém, a tensão de ruptura a $900{ }^{\circ} \mathrm{C}$ é maior do que de $800^{\circ} \mathrm{C}$. Pode-se destacar uma significativa diminuição da confiabilidade do material a $900{ }^{\circ} \mathrm{C}$ após a degradação $(\mathbf{m}=6,52)$. As amostras adicionadas com 10R possuem uma inclinação das retas superiores as porcentagens anteriores, garantido com isso, um material mais homogênio e confiável. Após a degradação, o módulo m diminui, mais intensamente, quando queimados a 800 ${ }^{\circ} \mathrm{C}$, de $\mathbf{m}=26,55$ para $\mathbf{m}=18,83$. Comparando-se com as adições de $0 R$ e $5 R$, verifica-se também um aumento de resistência à flexão das peças (Fig. 10), em ambas as temperaturas. Houve um enrijecimento das amostras que sofreram degradação, com o deslocamento da reta para a direita. Isso pode ser explicado pelo ciclo de congelamento que as amostras foram submetidas em todo o processo durante as $1060 \mathrm{~h}$. Neste caso, a confiabilidade das amostras foi melhor a $900{ }^{\circ} \mathrm{C}$, onde o $\mathbf{m}$ reduziu menos que a $800{ }^{\circ} \mathrm{C}$.

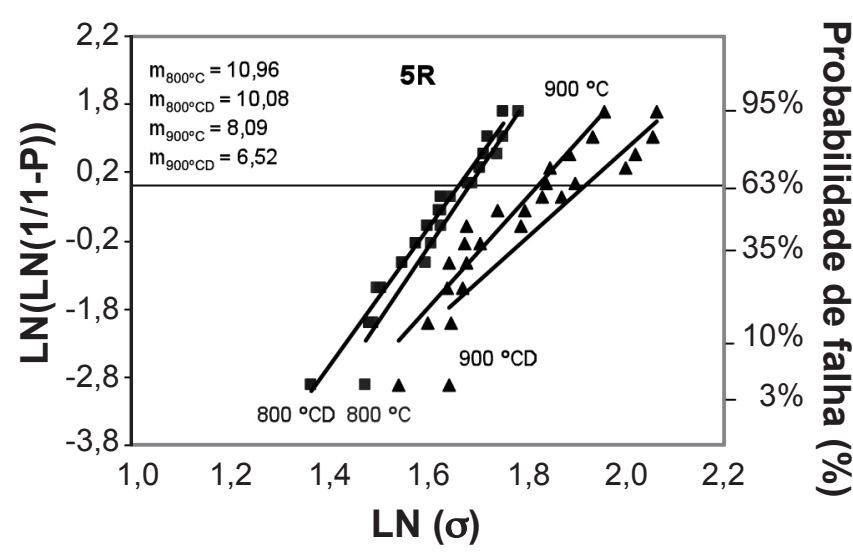

Figura 9: Distribuição de Weibull para as peças cerâmicas 5R. [Figure 9: Weibull distribuction of the specimens 5R.] 


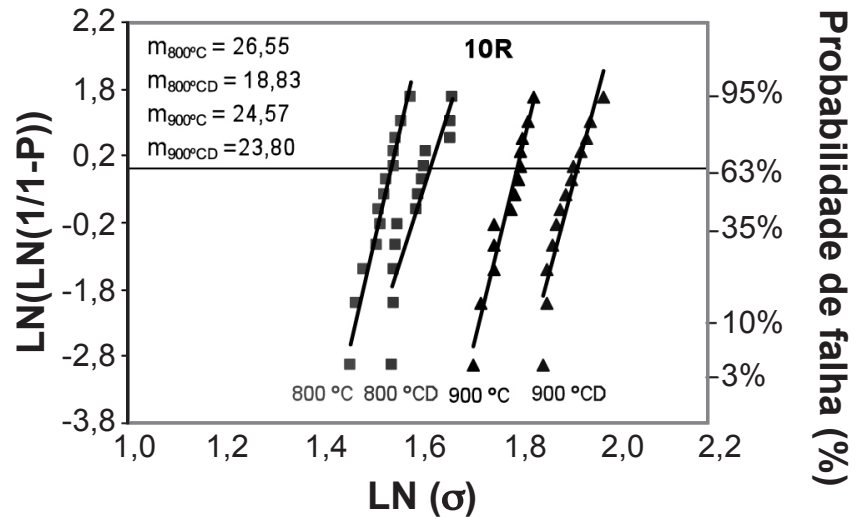

Figura 10: Distribuição de Weibull para as peças cerâmicas com adição de $10 \%$ de rejeito em massa.

[Figure 10: WeibulldDistribuction of the specimens 10R.]

\section{CONCLUSÕES}

A curva de distribuição granulometrica da argila é típica um material para uso em cerâmica vermelha (fração argila $53,3 \%$ ), e que o rejeito de rocha possui distribuição do tamanho de partículas correspondente a fração silte (67\%) adequado ao uso em cerâmica vermelha. As análises química e mineralógica mostraram que se trata de uma argila predominantemente caulinítica $\left(\mathrm{SiO}_{2}+\mathrm{Al}_{2} \mathrm{O}_{3}>84 \%\right)$, com a presença de óxidos fundentes $\left(\mathrm{K}_{2} \mathrm{O}+\mathrm{CaO}>3,70 \%\right)$ e que o rejeito de rocha, composto de minerais primários (quartzo, ortoclásio e minerais do grupo da mica), é proveniente de rocha básica, por apresentar valores de $\mathrm{SiO}_{2}<75 \%$. A adição de rejeito de rocha na massa cerâmica proporcionou uma diminuição da absorção de água e porosidade aparente das peças, principalmente na temperatura de queima de $900{ }^{\circ} \mathrm{C}$. A variação linear foi pequena nas diferentes temperaturas, reduzindo-se quando se adiciona o rejeito. A massa específi-ca sofreu um processo inverso com o incremento do rejeito. Em relação a resistência a flexão verificou-se um aumento com a adição de rejeito, mais significativamente com $10 \mathrm{R}$. Após degradação, somente as amostras com $0 \mathrm{R}$ a $800{ }^{\circ} \mathrm{C}$ sofreram redução em suas tensões de ruptura. Na temperatura de $800{ }^{\circ} \mathrm{C}$ obteve-se maior módulo de Weibull em todas as porcentagens de adição de rejeito de rocha na massa cerâmica. É evidente o melhor comportamento mecânico da peça com a 10R. Obteve-se em todos os resultados um aumento da tensão de ruptura. Levando em consideração a durabilidade e confiabilidade do material, afirma-se que as amostras queimadas a $900{ }^{\circ} \mathrm{C}$, com adição de $10 \mathrm{R}$ é o mais indicado para utilização em cerâmica vermelha. Deve-se ressaltar que isso é válido para este rejeito de rocha, podendo mudar quando se utilizar outro tipo de rejeito. Resultados diferentes foram observados [21] tendo sido indicado o uso de 5\% de rejeito de rocha ornamental na massa de conformação de cerâmica vermelha. Isso provavelmente se deve ao fato do rejeito de rocha utilizado nesta pesquisa estar isento de granalha.

\section{AGRADECIMENTOS}

Os autores agradecem o apoio financeiro do PIBIC/ UENF e da FAPERJ.

\section{REFERÊNCIAS}

[1] Abirochas - Associação Brasileira da Indústria de Rochas Ornamentais, Situação atual e perspectivas brasileiras no setor de rochas ornamentais, Informe 4 (2008).

[2] F. Saboya Jr., G. C. Xavier, J. Alexandre, The use of the powder marble by-product to enhance the properties of brick ceramic, Construction Building Mater. 21 (2007) 1950-1960.

[3] Sindirochas - Sindicato da Indústria de Rochas Ornamentais, Cal e Calcário do Estado do Espírito Santo (2007).

[4] C. M. F. Vieira, D. N. Henriques, C. C. Peiter, E. A. Carvalho, S. N. Monteiro, Utilização de gnaisse fino em massa cerâmica para telhas, Rev. Matéria 11, 3 (2006) 6p. [5] S. N. Monteiro, L. A. Pessanha, C. M. F. Vieira, Reformulation of roofing tiles body with addition of granite waste from sawing operations, J. Eur. Ceram. Soc. 8, 3 (2002) 2349-2356.

[6] A. J. Souza, B. C. A. Pinheiro, J. N. F. Holanda, Recycling of gneiss rock waste in the manufacture of vitrified floor tiles, J. Environmental Management 91 (2010) 685-689.

[7] R. R. Menezes, H. S. Ferreira, G. A. Neves, H. C. Ferreira, Uso de rejeitos de granito como matérias-primas cerâmicas, Cerâmica 48, 306 (2003) 757-761.

[8] E. T. A. Souza, S. N. Monteiro, C. M. F. Vieira, Revestimento cerâmico com granito e argila caulinítica, Cerâmica 50, 314 (2004) 122-127.

[9] G. C. Xavier, F. A. J. Saboya, P. C. A. Maia, J. Alexandre, Estudo da alteração de peças cerâmicas incorporadas com resíduo de granito através do ensaio de ciclos de umidade - Parte III, Anais $53^{\circ}$ Cong. Bras. Ceram., Guarujá, SP (2009) 10p.

[10] R. S. Mesquita, G. C. Xavier, F. A. J. Saboya, P. C. A. Maia, J. Alexandre, Degradação de cerâmica vermelha com adição de coque de petróleo, Anais $53^{\circ}$ Cong. Bras. Ceram., Guarujá, SP (2009) 12p.

[11] A. A. Griffith, Phil. Trans. Roy. Soc. 221A (1920). [12] G. P. Souza, R. Sanchez, J. N. F. Holanda, Characteristics and physical-mechanical properties of fired kaolinitic materials, Cerâmica 48, 306 (2002) 102107.

[13] C. M. F. Vieira, R. Sanchez, S. N. Monteiro, Characteristics of clays and properties of building ceramics in the State of Rio de Janeiro, Brazil, Construction Building Mater. 22 (2008) 781-787.

[14] ABNT, Associação Brasileira de Normas Técnicas, Determinação da análise granulométrica dos solos, NBR - 7181 (1984).

[15] J. Alexandre, Análise de matérias-primas e 
composições de massa utilizada em cerâmicas vermelhas, Tese Dr. UENF, Campos dos Goytacazes, RJ (2000) 174p. [16] ABNT, Associação Brasileira de Normas Técnicas, Solo - Determinação do limite de liquidez, NBR -6459 (1984).

[17] F. S. Manhães, F. A. J. Saboya, G. C. Xavier, J. Alexandre, Planejamento fatorial $3^{2}$ no estudo de peças cerâmicas vermelhas laminadas (0, 1 e 2 vezes) para fabricação de lajotas cerâmicas, Anais $48^{\circ}$ Cong. Bras. Ceram., Curitiba, PR (2004) 8p.

[18] ASTM C 373, Standard test method for water absorption, bulk density, apparent porosity and apparent specific gravity of fired whiteware products (1977a).

[19] ASTM C 674, Standard test method for flexural properties of ceramic whiteware materials (1977b).

[20] C. M. F. Vieira, T. M. Soares, R. Sánchez, S. N. Monteiro, Mater. Sci. Eng. (2003) 7p.

[21] G. C. Xavier, F. Saboya, P. C. A. Maia, J. Alexandre, Análise de processos de degradação acelerada em laboratório para estudo de durabilidade de peças cerâmicas vermelhas incorporadas com resíduo de granito, Cerâmica 55, 331 (2009) 1-10.

(Rec. 23/07/2011, Rev. 26/08/2011, Ac. 29/08/2011) 